Research Article

\section{Impact of Pacemaker Implantation on 12-Month Resource Utilization Following TAVR Hospitalization}

\author{
${ }^{1}$ Rollins School of Public Health, Emory University, Atlanta, Georgia \\ ${ }^{2}$ Baystate Health, Springfield MA, USA \\ ${ }^{3}$ Saint Luke's Mid America Heart Institute, Kansas City MO, USA \\ ${ }^{4}$ Harvard Baim Institute for Clinical Research, Boston MA, USA \\ ${ }^{5}$ CDS Research, LLC, USA \\ ${ }^{6}$ AWS Research, LLP, Indianapolis, Indiana, USA \\ ${ }^{7}$ Medical University of South Carolina, Charleston, SC, USA
}

Steven D Culler ${ }^{1 *}$, Aaron D Kugelmass ${ }^{2}$, David J Cohen ${ }^{3}$, Matthew R Reynolds ${ }^{4}$, Phillip P Brown ${ }^{5}$, April W Simon ${ }^{6}$ and Marc R Katz ${ }^{7}$

\section{Abstract}

Purpose: This study reports resource utilization during a Medicare Beneficiary's (MBs) Transcatheter Aortic Valve Replacement (TAVR) index hospitalization and all subsequent encounters for 12 months and compares data between MBs who did or did not receive a pacemaker implantation (PPM) during their index hospitalization.

Method: This retrospective study examined Medicare hospital claims from January 1, 2014 through June $30,2015.15,533$ MBs who survived for 365 days were studied. Information from all encounters during the study period was combined to compare hospital resource utilization and outcomes.

Results: $14.8 \%$ of MBs had a PPM during the index hospitalization. $46.0 \%$ of MBs had at least one readmission to a hospital during the 365 -day follow-up period. $54.6 \%$ of MB's first hospital readmission occurred within 90 days of their TAVR discharge date. Average total Medicare reimbursement for all hospitalizations was $\$ 60,638 \pm \$ 28,974$ associated with average total hospital length of stay of $11.2 \pm 11.7$ days. After adjusting for demographics and 47 comorbid conditions, MBs receiving a PPM during the index TAVR had significantly higher estimated Medicare reimbursement $(\$ 5,132)$ and longer total length of stay (1.8 days) for the entire study period than MBs not receiving a PPM.

Conclusion: Total Medicare reimbursement and hospital LOS were significantly higher among MBs that had a PPM implantation during their index admission; however, there were no significant differences in readmission rates, readmission length of stay, or days to first readmission during the follow-up period between the two study cohorts.

\section{More Information}

*Address for Correspondence: Steven D Culler, Rollins School of Public Health, Emory University, Atlanta, Georgia, 1815 Clifton Road, NE, Atlanta, GA 30322, Tel: (404) 727-3170;

Email: sculler@emory.edu

\author{
Submitted: 10 September 2019 \\ Approved: 18 October 2019 \\ Published: 21 October 2019
}

How to cite this article: Culler SD, Kugelmass AD, Cohen DJ, Reynolds MR, Brown PP, et al. Impact of Pacemaker Implantation on 12-Month Resource Utilization Following TAVR Hospitalization. J Cardiol Cardiovasc Med. 2019; 4: $164-170$.

DOI: dx.doi.org/10.29328/journal.jccm. 1001060

Copyright: @ 2019 Culler SD, et al. This is an open access article distributed under the Creative Commons Attribution License, which permits unrestricted use, distribution, and reproduction in any medium, provided the original work is properly cited

Keywords: TAVR; Medicare reimbursement Episode of care; Hospital resources

Abbreviations and Acronyms: DRG: Diagnosis Related Group; ICD: Implantation of VardioverterDefibrillator; ICD-9-CM: International Classification of Disease, $9^{\text {th }}$ Edition Clinical Modifications; IPSAF: Inpatient Standard Analytical Files; LOS: Length of Stay; MBs: Medicare Beneficiaries; OPSAF: Outpatient Standard Analytical Files; PPM: Pacemaker Implantation; SAVR: Surgical Aortic Valve Replacement; TARV: Transcatheter Aortic Valve Replacement

Check for updates

\section{Introduction}

Transcatheter aortic valve replacement (TAVR) offers a less invasive approach than surgical aortic valve replacement (SAVR) to treat severe aortic stenosis in patients with intermediate or high surgical risk from conventional SAVR, or for whom SAVR is contraindicated [1-5]. With similar primary clinical outcomes for TAVR as SAVR in inoperable, high and intermediate risk patients, there has been a sharp rise in the number of TAVR procedures being performed [4,6,7], especially among Medicare Beneficiaries (MBs) [8].
TAVR's cost effectiveness and value in high risk patients has been evaluated [9-12]. Patients with a high risk profile undergoing an index TAVR procedure experience shorter inpatient lengths of stay (LOS) than SAVR, however, procedural costs including the acquisition cost for the transcatheter valve, have resulted in higher index hospital costs [12]. Periprocedural complications experienced during an index TAVR hospitalization have been described, and impact TAVR's effective cost [11].

An important clinical complication associated with TAVR 
is atrioventricular conduction disturbance that requires permanent pacemaker implantation (PPM) [13,14]. PPM following TAVR is associated with higher index hospitalization cost due to both procedural cost and increased LOS $[11,14]$. In addition; PPM post-TAVR has been reported to increase the risk of unexpected hospital re-admission $[13,15,16]$.

From a hospital's financial risk perspective, the U.S. Centers for Medicare and Medicaid Services has identified cardiac valve procedures for voluntary bundled payment beginning in October 2018 and extending to December 2023 [17]. Reimbursement under a shared risk arrangement merits an understanding of resources consumed by MBs during an episode of care that includes an index TAVR procedure and extends through post-discharge follow-up.

In light of this context, this study divides MBs into two study cohorts: those who received a PPM during their index TAVR hospitalization and those who did not. Resource utilization is reported for both groups using the metrics of hospital length of stay and Medicare reimbursement for three time periods: the MBs' index TAVR hospitalization, the 365day post-discharge follow-up period, and the total episode of care. Additionally, the most common reasons for hospital readmission are reported for all MBs, which may be of use to hospitals seeking to reduce costly readmissions. Of note, during the study period approval for MB TAVR procedures was limited to the "high risk" patient cohort.

\section{Methods}

\section{Data source}

Centers for Medicare and Medicaid Service's Inpatient and Outpatient Standard Analytical Files (IPSAF and OPSAF) linked data for calendar years 2014, 2015, and 2016 are the data sources for this retrospective analysis. These files allow researchers to link all acute care and outpatient services utilized for an individual MB. The IPSAF data file contained information to calculate length of stay in days, discharge status, total Medicare reimbursement, International Classification of Disease, $9^{\text {th }}$ or $10^{\text {th }}$ Edition Clinical Modification (ICD-9-CM or ICD-10-CM) diagnoses and procedures codes, and diagnosis related category (DRG). While the OPSAF data file contains procedure codes to identify PPM or cardioverter-defibrillator (ICD) implantation performed in the outpatient setting during the study period, but Medicare reimbursement for outpatient episodes was not collected.

\section{Study population}

The population in this study consists of MBs in the IPSAF who underwent TAVR in a US hospital between January 1, 2014 and June 30, 2015. MBs undergoing TAVR were identified using the following ICD-9-CM procedure code: 35.05. A total of 20,682 TAVR hospitalizations were identified as meeting the inclusion criteria. A MB's TAVR hospitalization was excluded from the study population for four reasons: 1) the MB's
TAVRs hospitalization's discharge date was missing ( $\mathrm{n}=7)$; 2) the TAVR procedure identified was not the MBs first TAVR hospitalization in the study period ( $n=13)$; 3 ) the MB had a previous PPM or ICD ( $\mathrm{n}=2,844)$; or 4 ) the MB died during the index hospitalization or the follow-up period $(n=2,292)$. Because seven MBs were excluded for multiple reasons, the final study sample consists of 15,533 who survived for 365 days following their first TAVR procedure between January 1, 2014 and June 30, 2015. Two study cohorts were created based on whether or not the MBs received a permanent pacemaker implantation (PPM) identify by ICD-9-CM codes (37.80, 37.81. 37.82, 37.82, 37.83, 37.85, 37.86, 37.87, 00.50 or 00.53 ) during their index TAVR hospitalization.

\section{Unit of analysis and analytical file}

The unit of analysis is a MB. To construct the analytical file, the hospital file was searched to identify each MB's initial TAVR hospitalization, including all relevant utilization, reimbursement, and discharge destination information associated with the index TAVR. Next, the IPSAF and OPSAF hospital files for 2014, 2015, and 2016 were searched for all encounters within 365 days of the discharge date of the index TAVR hospitalization. A MB's claims were converted into a beneficiary level file by summing, averaging or counting the relevant data information obtained from all follow-up encounters. If a MB did not have any hospital readmissions or outpatient procedures all relevant study information was set equal to zero for that MB.

\section{Statistical analysis}

Univariate differences between MBs who did and did not receive a PPM during their index TAVR hospitalization were assessed using $\chi^{2}$ analysis or the Fisher exact test when $\chi^{2}$ analysis could not be performed due to expected counts less than five. Observed resource utilization statistics were reported as mean $\pm \mathrm{SD}$, median, first quartile, and third quartile values. Differences in resource utilization were tested using one-way ANOVA statistic with median score (number of points above the median). Differences between study groups were considered statistically different if the p-value was less than or equal to 0.001 . Median regression models were run to estimate risk-adjusted differences in median resource usage between the two study groups after controlling for demographic characteristics and 47 comorbid conditions. All analyses were performed with SAS 9.4 (SAS Institute, Cary, North Carolina).

\section{Demographic and comorbidity controls}

All demographic and comorbid conditions were created based on information contained in the claim information associated with the index TAVR hospitalization. Demographic variables of interest included: age group (under 65, 65 to 69, 70 to 74,75 to 79 , and 80 plus), gender, and race (white, or non-white). All comorbid conditions were identified using ICD-CM-9 or ICD-CM-10 codes that were present on admission during the index hospitalization. 


\section{Results}

Overall, MBs undergoing a TAVR during the study period were most likely to be older than 80 (69\%), white (93\%) and male (51\%) (Table 1). In addition, MBs during their index TAVR reported a variety of comorbid conditions, Table 1 reports on 19 different conditions experienced by more than $10 \%$ of MBs in the study populations. A comparison of demographic conditions between the two study cohorts indicated significant differences in the age distribution (MBs receiving a PPM were more likely to be over 80 years of age (72.95\% versus $68.66 \%)$ and male (54.93\% vs $50.50 \%)$.

The average length of stay (LOS) for all MBs during their index TAVR hospitalization was $6.4 \pm 5.7$ days while the median length of stay was 5.0 days (interquartile range for LOS was 3.0 to 7.0 days) (Table 2). Medicare reimbursed hospitals an average of $\$ 50,822 \pm \$ 19,834$ for the index hospitalization and the median Medicare reimbursement was $\$ 48,530$ (interquartile range for reimbursement was $\$ 39,574$ to $\$ 59,307)$. The vast majority of MBs were discharged from their index TAVR hospitalization to one of three destinations: home $(39.9 \%)$, home with a home health agency $(32.5 \%)$, or skilled nursing facility (20.4\%).

A comparison of the two study cohorts indicated that MBs in the PPM cohort consumed more resources than those MBs not receiving a PPM during their index TAVR hospitalization. The observed differences were 7.9 vs 6.1 days for index LOS and $\$ 55,597$ vs $\$ 49,996$ for Medicare reimbursement, respectively, while the median values were 6.0 vs 4.0 days LOS and $\$ 55,597$ vs $\$ 49,996$ for Medicare reimbursement. The one-way ANOVA test indicates that significantly more observations were above the median value for MBs in the PPM cohort for both resource measures. Finally, MBs in the PPM cohort were significantly less likely to be discharged home $(29.4 \%$ vs $41.7 \%)$, and significantly more likely to be discharged to a home health agency (35.5\% vs 32.0\%), a skill nursing facility $(25.9 \%$ vs $19.5 \%)$ or a rehabilitation facility (6.9\% vs $4.8 \%)$.

Part A of table 3 provides study statistics on hospitalizations occurring during the 365-day follow-up period for all MBs in the study. Four findings are worth noting. First, 8,390

Table 1: Baseline demographic and coronary risk factors present in more than $10 \%$ of MBs undergoing a TAVR index hospitalization or for factors with significantly differences between study cohorts.

\begin{tabular}{|c|c|c|c|c|}
\hline & \multirow[b]{2}{*}{ All MBs } & \multicolumn{2}{|c|}{ Received Pacemaker Implantation } & \multirow[b]{2}{*}{$p$ - value } \\
\hline & & Yes & No & \\
\hline & $(n=15,533)$ & $(n=2,292)$ & $(n=13,241)$ & \\
\hline \multicolumn{5}{|l|}{ Age (age categories) } \\
\hline$<65, \%$ & 1.79 & 1.66 & 1.81 & \\
\hline $65-69, \%$ & 5.09 & 3.49 & 5.37 & \\
\hline $70-74, \%$ & 9.08 & 8.03 & 9.26 & \\
\hline $75-79, \%$ & 14.75 & 13.87 & 14.90 & \\
\hline$\geq 80, \%$ & 69.29 & 72.95 & 68.66 & $p<0.001$ \\
\hline \multicolumn{5}{|l|}{ Gender } \\
\hline Male, \% & 51.16 & 54.93 & 50.50 & $p<0.001$ \\
\hline \multicolumn{5}{|l|}{ Race } \\
\hline White & 92.72 & 93.15 & 92.64 & \\
\hline Non-white & 7.28 & 6.85 & 7.36 & $p=0.389$ \\
\hline \multicolumn{5}{|l|}{ Comorbidities } \\
\hline Obesity, \% & 16.09 & 16.45 & 16.03 & $p=0.618$ \\
\hline Body mass index greater than $30, \%$ & 12.02 & 11.87 & 12.05 & $p=0.808$ \\
\hline Type II diabetes mellitus, \% & 36.36 & 38.48 & 35.99 & $p=0.022$ \\
\hline History of smoking, $\%$ & 29.47 & 29.01 & 29.54 & $p=0.607$ \\
\hline Heart failure, $\%$ & 75.11 & 76.00 & 74.96 & $p=0.285$ \\
\hline Chronic ischemic heart disease, $\%$ & 71.61 & 72.86 & 71.37 & $p=0.150$ \\
\hline Prior myocardial infarction & 12.88 & 12.13 & 13.01 & $p=0.248$ \\
\hline Hypertension & 87.25 & 86.04 & 87.46 & $p=0.059$ \\
\hline Chronic obstructive pulmonary disease, $\%$ & 32.34 & 30.37 & 32.68 & $p=0.029$ \\
\hline Moderate chronic kidney disease, $\%$ & 17.70 & 18.59 & 17.54 & $p=0.227$ \\
\hline Chronic kidney disease, unspecified, \% & 10.90 & 10.34 & 11.00 & $p=0.352$ \\
\hline Peripheral vascular disease, $\%$ & 23.65 & 23.25 & 23.71 & $p=0.633$ \\
\hline Hyperlipidemia, \% & 69.47 & 69.90 & 69.39 & $p=0.628$ \\
\hline Atrial fibrillation, $\mathrm{POA}, \%$ & 35.70 & 38.57 & 39.20 & $p=0.002$ \\
\hline Heart Block, POA, \% & 14.80 & 26.57 & 12.76 & $p<0.001$ \\
\hline RBBB Block, POA, \% & 3.30 & 7.72 & 2.53 & $p<0.001$ \\
\hline LBBB, Block, POA, \% & 6.31 & 6.46 & 6.28 & $p=0.752$ \\
\hline Other Conduction Disorder, POA, \% & 6.98 & 16.56 & 5.32 & $p<0.001$ \\
\hline Prior $\mathrm{PCl}, \%$ & 22.09 & 22.99 & 21.93 & $p=0.258$ \\
\hline Prior CABG, \% & 22.94 & 22.77 & 22.97 & $p=0.840$ \\
\hline Anemia, POA \% & 27.61 & 26.96 & 27.72 & $p=0.452$ \\
\hline Prior cerebral vascular accident, $\%$ & 11.83 & 11.82 & 11.83 & $p=0.988$ \\
\hline
\end{tabular}


Table 2: Observed Index Hospital Resources, Outcomes, and Discharge Status of Medicare Beneficiaries during their Index TAVR Hospitalization and by whether or not the Medicare Beneficiary Received a Pacemaker Implantation.

\section{\begin{tabular}{|l|l|l|l}
\hline PPM Implanted during TAVR & No PPM Implanted during TAVR \\
\hline
\end{tabular}}

\begin{tabular}{|c|c|c|c}
\hline All MBs & PPM Implanted during TAVR & No PPM Implanted during TAVR & $p-$ value \\
& Admission & Admission &
\end{tabular}

Total Average Resource Utilization Statistics associated with index TAVR hospitalization:

Length of Stay
Mean \pm Std.
Median Value
$1^{\text {st }}$ Quartile Value
$3^{\text {rd }}$ Quartile Value

$6.4 \pm 5.7$
5.0
3.0
7.0

$7.9 \pm 6.1$
6.0
4.0
9.0
$6.1 \pm 5.6$
4.0
3.0
7.0

Medicare Reimbursement

Mean \pm Std.

Median Value

$1^{\text {st }}$ Quartile Value

$3^{\text {rd }}$ Quartile Value

$\$ 50,823 \pm \$ 19,834$
$\$ 48,530$
$\$ 39,574$
$\$ 59,307$

$\$ 55,597 \pm \$ 19,781$
$\$ 52,843$
$\$ 43,407$
$\$ 64,396$

$\$ 49,996 \pm \$ 19,727$

$\$ 47,504$

$\$ 38,987$

$\$ 58,169$

p - value

\section{Outcomes:}

Other Valve Procedures during Index TAVR:

\begin{tabular}{|c|c|c|c|}
\hline Other Valve Procedures during Index TAVR: & 0.00 & 0.06 & $0.614^{\star \star}$ \\
\hline Valvuloplasty, $\%$ & 0.05 & 0.39 & 0.17 \\
\hline Valve with Tissue, \% & 0.20 & 0.00 & $0.038^{\star \star}$ \\
\hline Valve with Other, $\%$ & 0.07 & $p=0.386^{\star \star}$
\end{tabular}

Hospital Discharge Destination:

\begin{tabular}{|c|c|c|}
\hline Home, \% & 39.9 & 29.4 \\
\hline Home Health Agency, \% & 32.5 & 35.5 \\
\hline Skilled Nursing Care, \% & 20.4 & 25.9 \\
\hline Rehabilitation Facility, \% & 5.1 & 2.4 \\
\hline Other Discharge Status, \% & 2.0 & 2.4 \\
\hline
\end{tabular}

\begin{tabular}{|c|c|c|}
\hline 29.4 & 41.7 & $p<0.001$ \\
\hline 35.5 & 32.0 & $p=0.001$ \\
\hline 25.9 & 19.5 & $p<0.001$ \\
\hline 6.9 & 4.8 & $p<0.001$ \\
\hline 2.4 & 2.0 & $p=0.180$ \\
\hline
\end{tabular}

${ }^{*} p$ - value reports the one-way ANOVA statistic for median score (points above the median). All other $p$ - values were calculated using the Chi-Squared test.

** More than $20 \%$ of cells had expected counts less than $5 ; p$-value instead reports a two-sided Fisher's exact test.

Table 3: Observed Hospital Resource Utilization Statistics of Medicare Beneficiaries during the 365-days following their Index TAVR Hospitalization and by whether or not the Medicare Beneficiary received a pacemaker implantation during their index TARV admission.

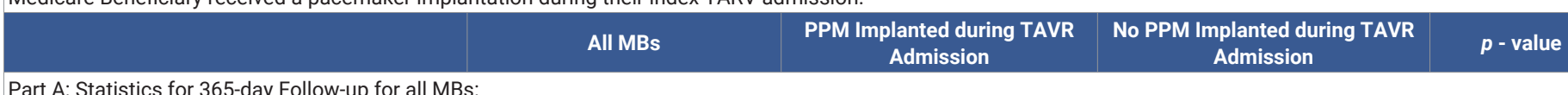

Number of Hospital Readmissions (MBs, \%):

\begin{tabular}{|c|c|c|c|c|}
\hline 0 & $8,390(54.0)$ & $1,258(54.9)$ & $7,132(53.9)$ & \multirow{5}{*}{$p=0.252$} \\
\hline 1 & $3,572(23.0)$ & $499(21.8)$ & $3,073(23.2)$ & \\
\hline 2 & $1,738(11.2)$ & $264(11.5)$ & $1,474(11.1)$ & \\
\hline 3 & $899(5.8)$ & $146(6.4)$ & $753(5.7)$ & \\
\hline 4 or more & $934(6.0)$ & $125(5.5)$ & $809(6.1)$ & \\
\hline Range of Hospital Visits & $0-15$ & $0-10$ & $0-15$ & $-N A-$ \\
\hline $\begin{array}{c}\text { Total LOS } \\
\text { Mean } \pm \text { Std. } \\
\text { Median Value } \\
3^{\text {rd }} \text { Quartile Value }\end{array}$ & $\begin{array}{c}4.83 \pm 9.38 \\
0 \\
6\end{array}$ & $\begin{array}{c}4.91 \pm 9.63 \\
0 \\
6\end{array}$ & $\begin{array}{c}4.82 \pm 9.34 \\
0 \\
6\end{array}$ & $p=0.213^{*}$ \\
\hline $\begin{array}{c}\text { Medicare Reimbursement } \\
\text { Mean } \pm \text { Std. } \\
\text { Median Value } \\
3^{\text {rd }} \text { Quartile Value }\end{array}$ & $\begin{array}{c}\$ 9,815 \pm \$ 18,898 \\
\$ 0.00 \\
\$ 12,647\end{array}$ & $\begin{array}{c}\$ 9,876 \pm \$ 19,239 \\
\$ 0.00 \\
\$ 13,074\end{array}$ & $\begin{array}{c}\$ 9,804 \pm \$ 18,839 \\
\$ 0.00 \\
\$ 12,592\end{array}$ & $p=0.129 *$ \\
\hline \multicolumn{5}{|c|}{ Part B: Statistics during 365-day Follow-up for MBs with at Least One Hospital Readmission: } \\
\hline Number of MBs & 7,143 & 1,034 & 6,109 & $-\mathrm{NA}-$ \\
\hline \multicolumn{5}{|c|}{ First Hospitalization during 365-day Follow-up Period: } \\
\hline $\begin{array}{c}\text { Average Days to First Readmiss } \\
\text { Mean } \pm \text { Std. } \\
\text { Median Value } \\
1^{\text {st }} \text { Quartile Value } \\
3^{\text {rd }} \text { Quartile Value }\end{array}$ & $\begin{array}{c}111.1 \pm 105.6 \\
75 \\
19 \\
185\end{array}$ & $\begin{array}{c}112.6 \pm 106.3 \\
74 \\
20 \\
187\end{array}$ & $\begin{array}{c}110.9 \pm 105.4 \\
75 \\
18 \\
185\end{array}$ & $p=0.445^{*}$ \\
\hline $\begin{array}{c}\text { Average LOS } \\
\text { Mean } \pm \text { Std. } \\
\text { Median Value } \\
1^{\text {st }} \text { Quartile Value } \\
3^{\text {rd }} \text { Quartile Value }\end{array}$ & $\begin{array}{c}4.85 \pm 4.70 \\
4.0 \\
2.0 \\
6.0\end{array}$ & $\begin{array}{c}5.23 \pm 5.59 \\
4.0 \\
2.0 \\
6.0\end{array}$ & $\begin{array}{c}4.78 \pm 4.53 \\
4.0 \\
2.0 \\
6.0\end{array}$ & $p=0.136^{\star}$ \\
\hline \multicolumn{5}{|c|}{ Distribution of Days to First Readmission (\% (count of MBs)): } \\
\hline Same Day Readmission & $0.5 \%(38)$ & $1.3 \%(13)$ & $0.4 \%(25)$ & $p<0.001$ \\
\hline 1 to 30 Days & $31.8 \%(2,273)$ & $30.1 \%(311)$ & $32.1 \%(1,962)$ & $p=0.193$ \\
\hline 31 Days to 90 Days & $22.3 \%(1,589)$ & $23.8 \%(246)$ & $22.0 \%(1,343)$ & $p=0.196$ \\
\hline 91 Days to 180 Days & $19.5 \%(1,392)$ & $18.7 \%(193)$ & $19.6 \%(1,199)$ & $p=0.471$ \\
\hline
\end{tabular}




\begin{tabular}{|c|c|c|c|c|}
\hline 181 Days to 360 Days & $25.9 \%(1,851)$ & $26.2 \%(271)$ & $25.9 \%(1,580)$ & $p=0.815$ \\
\hline \multicolumn{5}{|c|}{ Part C: All Hospitals during 365 day Follow-up Period: } \\
\hline $\begin{array}{c}\text { Total LOS } \\
\text { Mean } \pm \text { Std. } \\
\text { Median Value } \\
1^{\text {st }} \text { Quartile Value } \\
3^{\text {rd }} \text { Quartile Value }\end{array}$ & $\begin{array}{c}10.5 \pm 11.5 \\
7.0 \\
3.0 \\
13.0\end{array}$ & $\begin{array}{c}10.9 \pm 11.9 \\
7.0 \\
3.0 \\
14.0\end{array}$ & $\begin{array}{c}10.4 \pm 11.4 \\
7.0 \\
3.0 \\
13.0\end{array}$ & $p=0.082^{*}$ \\
\hline $\begin{array}{c}\text { Medicare Reimbursement } \\
\text { Mean } \pm \text { Std. } \\
\text { Median Value } \\
1^{\text {st }} \text { Quartile Value } \\
3^{\text {rd }} \text { Quartile Value }\end{array}$ & $\begin{array}{c}\$ 21,343 \pm \$ 23,034 \\
\$ 14,113 \\
\$ 7,451 \\
\$ 26,587\end{array}$ & $\begin{array}{c}\$ 21,891 \pm \$ 23,615 \\
\$ 14,662 \\
\$ 7,548 \\
\$ 27,236\end{array}$ & $\begin{array}{c}\$ 21,250 \pm \$ 22,935 \\
\$ 13,966 \\
\$ 7,451 \\
\$ 26,538\end{array}$ & $p=0.089 *$ \\
\hline \multicolumn{5}{|l|}{ Valve Procedures during 365-day follow-up period: } \\
\hline Any Valve, \% (Count) & $1.50(107)$ & $1.74(18)$ & $1.46(89)$ & $p=0.487$ \\
\hline Any TAVR, \% (Count) & $1.06(76)$ & $1.26(13)$ & $1.03(63)$ & $p=0.513$ \\
\hline Any SAVR, \% (Count) & $0.34(24)$ & $0.39(4)$ & $0.33(20)$ & $p=0.760$ \\
\hline \multicolumn{5}{|c|}{ Any PPM or ICD Procedures (Inpatient or Outpatient) during 365-day follow-up period: } \\
\hline PPM, \% (Count) & $3.94(612)$ & $1.27(29)$ & $4.40(583)$ & $p<0.001$ \\
\hline ICD, \% (Count) & $0.82(128)$ & $0.52(12)$ & $0.88(116)$ & $p=0.102$ \\
\hline \multicolumn{5}{|c|}{ Most Frequent Reason for Hospital Readmission in Selected DRG Category: } \\
\hline $\begin{array}{l}\text { Pulmonary Edema \& Respiratory Failure, \% } \\
\text { (Count) }\end{array}$ & $23.1(1,648)$ & $28.1(291)$ & $22.2(1,357)$ & $p<0.001$ \\
\hline Heart Failure, \% (Count) & $21.5(1,534)$ & $27.2(281)$ & $20.5(1,253)$ & $p<0.001$ \\
\hline Sepsis, \% (Count) & $11.2(799)$ & $10.2(105)$ & $11.4(694)$ & $p=0.255$ \\
\hline COPD/Pneumonia, \% (Count) & $10.5(749)$ & $9.5(98)$ & $10.7(651)$ & $p=0.253$ \\
\hline GI Bleed with Hemorrhage, \% (Count) & $8.6(617)$ & $8.6(89)$ & $8.6(528)$ & $p=0.970$ \\
\hline Renal Failure, \% (Count) & $5.9(418)$ & $5.6(58)$ & $5.9(360)$ & $p=0.719$ \\
\hline Arrhythmia, \% (Count) & $6.1(433)$ & $4.6(48)$ & $6.3(385)$ & $p=0.039$ \\
\hline Urinary Track, \% (Count) & $5.4(387)$ & $6.5(67)$ & $5.2(320)$ & $p=0.103$ \\
\hline
\end{tabular}

(54.0\%) of the MBs surviving the study period did not have any hospitalizations during the follow-up period. 3,572 MBs (23.0\%) experienced only one hospitalization during the follow-up period. However, $11.8 \%$ of MBs had three or more hospitalizations during the follow-up period (maximum was 15 hospitalizations). Second, amongst all MBs, the average total hospital LOS during the follow-up period was $4.83 \pm 9.38$ days. Third, average total hospital reimbursement for all MBs during the follow-up period was $\$ 9,815 \pm \$ 18,898$. Note the median LOS and Medicare reimbursement were both 0 as $54 \%$ of the MBs did not have a readmission. Finally, the oneway ANOVA test indicates no significantly differences in the number of observations above the median value for either resource measure between the two-study cohorts.

Part B of table 3 reports study resource statistics among the 7,143 MBs first hospitalization during the follow-up period. Approximately $32 \%$ of MBs had their first readmission within 30 days of their index TAVR. On the other hand, approximately $26 \%$ of the MBs first hospital readmission did not occur until at least 181 days after their TAVR discharge. On average, the first hospital readmission occurred 111.1 \pm 105.6 days after discharge from their index TAVR, while the median numbers to the first readmission was 75 days (interquartile range 19 to 185 days). Part $\mathrm{C}$ of table 3 reports resource utilization on all hospitalizations during the 365-day follow-up period among MBs that experienced at least one hospitalization. The average total LOS during the entire follow-up period among MBs with a hospitalization was $10.5 \pm 11.5$ (median 7 days, interquartile range 3 to 13 days) and average total Medicare reimbursement was $\$ 21,343 \pm \$ 23,034$ (median $\$ 14,113$, interquartile range $\$ 7,451$ to $\$ 26,587$ ). The one-way AVOVA test found no significant differences in the distribution of any of these resource measures during the follow-up period between the two study cohorts in table 3. It is interesting to note that during the follow-up period, $107 \mathrm{MBs}$ (1.5\%) had an additional valve procedure, of which 76 had a second TAVR procedure. Further, the four most common reasons (based on DRG categories) for hospital readmissions during the followup period were: pulmonary edema and respiratory failure (23.1\%), heart failure (21.5\%), sepsis (11.2\%) and COPD or pneumonia $(10.5 \%)$. MBs in the PPM cohort were significantly more likely to have a readmission associated with pulmonary edema and respiratory failure $(28.1 \%$ vs $22.2 \%)$ and heart failure (27.2\% vs $20.5 \%)$.

Table 4 reports total hospital resource utilization by combining the index TAVR hospitalization with the 365day follow-up period. Part A indicates that average total hospital LOS was $11.2 \pm 11.7$ days and median LOS was 7.0 days (interquartile range 4.0 to 14.0 days) during the entire episode. Average total Medicare reimbursement was $\$ 60,638$ $\pm \$ 28,974$ and median Medicare reimbursement was $\$ 54,849$ (interquartile range $\$ 43,236$ to $\$ 71,007$ ). Overall, the index TAVR hospitalization accounted for approximately $84 \%$ of all Medicare reimbursement during the study period. The oneway ANOVA test indicates that significantly more observations in the distributions for LOS and Medicare reimbursement were above the median value for MBs in the PPM cohort. 
Table 4: Observed and Risk-Adjusted Hospital Resource Utilization during the Entire Study Period for all Medicare Beneficiaries and by whether or not the Medicare Beneficiary received a pacemaker implantation during their index TARV admission.

\begin{tabular}{|c|c|c|c|c|}
\hline & All MBs & PPM Implanted during TAVR Admission & $\begin{array}{c}\text { No PPM Implanted during TAVR } \\
\text { Admission }\end{array}$ & $p$ - value* \\
\hline Number of MBs & 15,533 & 2,292 & 13,241 & $-\mathrm{NA}-$ \\
\hline \multicolumn{5}{|c|}{ Part A: Observed Resource Utilization Statistics during Study Period: } \\
\hline $\begin{array}{l}\text { Length of Stay } \\
\text { Mean } \pm \text { Std. } \\
\text { Median Value } \\
1^{\text {st }} \text { Quartile Value } \\
3^{\text {rd }} \text { Quartile Value }\end{array}$ & $\begin{array}{c}11.2 \pm 11.7 \\
7.0 \\
4.0 \\
14.0\end{array}$ & $\begin{array}{c}12.8 \pm 12.1 \\
9.0 \\
5.0 \\
16.0\end{array}$ & $\begin{array}{c}10.9 \pm 11.6 \\
7.0 \\
4.0 \\
14.0\end{array}$ & $p<0.001$ \\
\hline $\begin{array}{l}\text { Reimbursement } \\
\text { Mean } \pm \text { Std. } \\
\text { Median Value } \\
1^{\text {st }} \text { Quartile Value } \\
3^{\text {rd }} \text { Quartile Value }\end{array}$ & $\begin{array}{c}\$ 60,638 \pm \$ 28,974 \\
\$ 54,849 \\
\$ 43,236 \\
\$ 71,007\end{array}$ & $\begin{array}{c}\$ 65,473 \pm \$ 29,053 \\
\$ 59,756 \\
\$ 47,342.50 \\
\$ 77,196.50\end{array}$ & $\begin{array}{c}\$ 59,801 \pm \$ 28,879 \\
\$ 54,019 \\
\$ 42,610 \\
\$ 69,712\end{array}$ & $p<0.001$ \\
\hline
\end{tabular}

Part B: Risk-Adjusted Median Regression Estimates of Resource Utilization during Study Period:

\begin{tabular}{|l|c|c|}
\hline & $\begin{array}{c}\text { Estimated Impact of Receiving PPM During Index } \\
\text { Admission*** }\end{array}$ & 1.84 \\
\hline $\begin{array}{l}\text { Length of Stay (days) } \\
(95 \% \text { Confidence Interval) }\end{array}$ & $(1.48$ to 2.20$)$ & $p<0.001$ \\
\hline $\begin{array}{l}\text { Medicare Reimbursement } \\
(95 \% \text { Confidence Interval) }\end{array}$ & $\$ 5,132$ & $(\$ 3,995$ to $\$ 6,270)$
\end{tabular}
(95\% Confidence Interval) $(\$ 3,995$ to $\$ 6,270)$

${ }^{*} p$ - values in Part A report the one-way ANOVA statistic for median score (points above the median).

${ }^{* \star} p$ - values in Part B report the result of the Median Regression for the indicator variable that a Medicare Beneficiary received a PPM during their index TAVR admission.

$\star \star \star$ Regression model controlled for all variables listed in table 1 and the following comorbid conditions: Body mass index less than 19, Type I diabetes mellitus, Current smoker, Acute renal failure, Unstable angina, Malnutrition, Dementia, Depression, Acute respiratory failure, chronic respiratory failure, Mild chronic kidney disease, Severe chronic kidnsey disease, Dialysis dependent, Chronic liver disease, Aortic Aneurysm, Cardiomyopathy, Cardiogenic shock, Cardiac arrest, Primary STEMI, Primary Non-STEMI, Prior value surgery, Prior venous thromboembolism, cancer, or AIDS.

Part B of table 4 reports estimated incremental resource utilization between the two study cohorts obtained from the risk-adjusted median regression models for total episode hospital LOS and Medicare reimbursement. The results of the median regression models indicate that median Medicare reimbursement was significantly higher $(\$ 5,132)$ and median LOS was significant longer (1.84) days in the PPM cohort after controlling for difference in demographic characteristics and observed comorbid conditions between the two study cohorts.

\section{Discussion}

This analysis reports a set of nationally representative Medicare benchmarks for a MB's index TAVR hospitalization and all hospital encounters during a 365-day follow-up period. First, total average Medicare reimbursement to hospitals among the 15,533 MBs undergoing a TAVR procedure was $\$ 60,638 \pm \$ 28,974$ for the entire study period. Average Medicare reimbursement for the index TAVR hospitalization accounted for $83.8 \%$ of total average reimbursement for the entire study period. Second, $54.0 \%(8,390)$ of the MBs undergoing a TAVR procedure did not have any hospital readmissions during the 365-day follow-up period. Third, MBs in the PPM cohort had higher average Medicare reimbursement during both the index TAVR hospitalization $(\$ 55,597 \pm \$ 19,781$ versus $\$ 49,996 \pm 19,727)$ and for the entire study period $(\$ 65,473 \pm \$ 29,053$ versus $\$ 59,801 \pm$ $\$ 28,879$ ) than MBs in the non-PPM cohort. Finally, this study provides insight into the clinical reasons associated with MBs having a hospitalization following TAVR. The two most common DRG categories for readmission were pulmonary edema/respiratory failure and heart failure.
This paper provides insights into the financial risks that healthcare providers will incur if a provider proceeds with a bundle payment program for TAVR procedures. After controlling for demographics and 47 comorbid conditions, this paper finds statistically significant longer total lengths of stay $(1,8$ days) and higher Medicare reimbursements $(\$ 5,132)$ for MBs receiving PPM implantations. This paper finds that nearly $55 \%$ of MBs first hospital readmission occurred within 90 days of the index TAVR hospitalization. Further, average Medicare reimbursement during follow-up hospitalization for all MBs with at least one readmission in this study was $\$ 21,343$ $\pm \$ 23,034$, approximately $42 \%$ of observed average Medicare reimbursement during the index TAVR hospitalization.

Furthermore, this paper provides insight into the clinical problems that resulted in readmissions during the follow-up period. In particular, this paper findings that over $4.0 \%$ of TAVR patients not receiving PPM during their index hospitalization underwent PPM procedures during the follow-up period. This finding supports concerns related to atrioventricular block following TAVR [18] and gives providers insight into potential bundling of devices from manufacturers to cover this additional cost. In addition, under bundled payments, it will be financially advantageous to manage the comorbid conditions associated with readmissions. Given that $44.6 \%$ of readmissions were due to pulmonary edema and respiratory failure or heart failure, there appears to be opportunity for outpatient intervention, remote monitoring, telemedicine follow-up or other preemptive maneuvers to help avoid these readmissions. Finally, this study found MBs in the PPM cohort were significantly more likely to use post-acute care, including home health agencies (35.5\% vs $32.0 \%)$, skilled nursing 
facilities (25.9\% vs $19.5 \%)$ and rehabilitation hospitals $(6.9 \%$ vs $4.8 \%)$ and less likely to be discharged home $(29.4 \%$ vs $41.7 \%)$.

Several limitations warrant discussion. First, this analysis applies only to MBs in the fee-for service program. A second limitation is that this study does not have any information concerning the resources consumed for using post-acute care services or outpatient procedures during the follow-up period. Another limitation of this study is Medicare reimbursement in this study is observed based on the payment rule and financial incentives in the Medicare program during 2014 to 2016. It is not possible to speculate how hospitals and other healthcare providers will change their patterns of care, in response to the new financial incentives associated with future Medicare's bundle payment programs and other value-based delivery models.

\section{References}

1. Leon MB, Smith CR, Mack MJ, Makkar RR, Svensson LG, et al. Transcatheter or surgical aortic-valve replacement in intermediate-risk patients. N Engl J Med. 2016; 374: 1609-1620.

PubMed: https://www.ncbi.nlm.nih.gov/pubmed/27040324

2. MackMJ, Leon MB, Smith CR, Miller DC, Moses JW, et al. 5-year outcomes of transcatheter aortic valve replacement or surgical aortic valve replacement forhigh surgical risk patients with aortic stenosis(PARTNER 1): a randomized controlled trial. Lancet. 2015; 385: 2477-2484.

PubMed: https://www.ncbi.nlm.nih.gov/pubmed/25788234

3. Kodali SK, Williams MR, Smith CR, Svensson LG, Webb JG, et al. Twoyear outcomes after transcatheter or surgical aortic-valve replacement. N Engl J Med. 2012; 366: 1686-1695.

PubMed: https://www.ncbi.nlm.nih.gov/pubmed/22443479

4. Holmes DR Jr, Nishimura RA, Grover FL, Brindis RG, Carroll JD, et al Annual outcomes with transcatheter valve therapy: from the STS/ACC TVT Registry. J Am Coll Cardiol. 2015; 66 2813-2823.

PubMed: https://www.ncbi.nlm.nih.gov/pubmed/26652232

5. Holmes DR Jr, Brennan JM, Rumsfeld JS, Dai D, O’Brien SM, et al. Clinical outcomes at 1 year following transcatheter aortic valve replacement. JAMA. 2015; 313: 1019-1028.

PubMed: https://www.ncbi.nlm.nih.gov/pubmed/25756438

6. Grover FL, Vemulapalli S, Carroll JD, Edwards FH, Mack MJ, et al. 2016 annual report of the society of thoracic surgeons/American college of cardiology transcatheter valve therapy registry. The Annals of Thoracic Surgery. 2017; 103: 1021-1035.

PubMed: https://www.ncbi.nlm.nih.gov/pubmed/27956264

7. Reinöhl J, Kaier K, Reinecke H, Schmoor C, Frankenstein L, et al. Effect of availability of transcatheter aortic-valve replacement on clinical practice. N Engl J Med. 2015; 373: 2438-2447.

PubMed: https://www.ncbi.nlm.nih.gov/pubmed/26672846

8. Culler SD, Cohen DJ, Brown PP, Kugelmass AD, Reynolds MR, et al. Trends in Aortic Valve Replacement Procedures Between 2009 and 2015: Has Transcatheter Aortic Valve Replacement Made a Difference?
Ann Thorac Surg. 2018; 105: 1137-1143.

PubMed: https://www.ncbi.nlm.nih.gov/pubmed/29394992

9. Reynolds MR, Magnuson EA, Lei Y, Wang K, Vilain K, et al. Costeffectiveness of transcatheter aortic valve replacement compared with surgical aortic valve replacement in high-risk patients with severe aortic stenosis: results of the PARTNER (Placement of Aortic Transcatheter Valves) trial (Cohort A). J Am Coll Cardiol. 2012; 60: 2683-2692.

PubMed: https://www.ncbi.nlm.nih.gov/pubmed/23122802

10. Reynolds MR, Magnuson EA, Wang K, Lei Y, Vilain K, et al. CostEffectiveness of Transcatheter Aortic Valve Replacement Compared With Standard Care Among Inoperable Patients With Severe Aortic Stenosis Clinical Perspective: Results From the Placement of Aortic Transcatheter Valves (PARTNER) Trial (Cohort B). Circulation. 2012; 125: 1102-1109.

PubMed: https://www.ncbi.nlm.nih.gov/pubmed/22308299

11. Arnold SV, Lei Y, Reynolds MR, Magnuson EA, Suri RM, et al. Costs of periprocedural complications in patients treated with transcatheter aortic valve replacement: results from the Placement of Aortic Transcatheter Valve trial. Circ Cardiovasc Interv. 2014; 7: 829-836. PubMed: https://www.ncbi.nlm.nih.gov/pubmed/25336467

12. Reynolds MR, Lei Y, Wang K, Chinnakondepalli K, Vilain KA, et al. Costeffectiveness of transcatheter aortic valve replacement with a selfexpanding prosthesis versus surgical aortic valve replacement. J Am Coll Cardiol. 2016; 67: 29-38.

PubMed: https://www.ncbi.nlm.nih.gov/pubmed/26764063

13. Fadahunsi OO, Olowoyeye A, Ukaigwe A, Li Z, Vora AN, et al. Incidence, predictors, and outcomes of permanent pacemaker implantation following transcatheter aortic valve replacement: analysis from the US Society of Thoracic Surgeons/American College of Cardiology TVT Registry. JACC Cardiovasc Interv. 2016; 9: 2189-2199.

PubMed: https://www.ncbi.nlm.nih.gov/pubmed/27832844

14. Siontis GC, Jüni $P$, Pilgrim T, Stortecky S, Büllesfeld L, et al. Predictors of permanent pacemaker implantation in patients with severe aortic stenosis undergoing TAVR: a meta-analysis. J Am Coll Cardiol. 2014; 64: 129-140.

PubMed: https://www.ncbi.nlm.nih.gov/pubmed/25011716

15. Kolte D, Khera S, Sardar MR, Gheewala N, Gupta T, et al. Thirty-day readmissions after transcatheter aortic valve replacement in the United States: insights from the nationwide readmissions database. Circ Cardiovasc Interv. 2017; 10: e004472.

PubMed: https://www.ncbi.nlm.nih.gov/pubmed/28034845

16. Chamandi C, Barbanti M, Munoz-Garcia A, Latib A, Nombela-Franco L, et al. Long-Term Outcomes in Patients With New Permanent Pacemaker Implantation Following Transcatheter Aortic Valve Replacement. JACC Cardiovasc Interv.. 2018; 11: 301-310.

PubMed: https://www.ncbi.nlm.nih.gov/pubmed/29413244

17. Centers for Medicare and Medicaid Services. Bundled Payments for Care Improvement Advanced (BPCl Advanced) Voluntary Bundled Payment Model.https://www.cms.gov/Newsroom/MediaReleaseDatabase/ Fact-sheets/2018-Fact-sheets-items/2018-01-10.html.

18. Ream K, Sandhu A, Valle J, Weber R, Kaizer A, et al. Ambulatory Rhythm Monitoring to Detect Late High-Grade Atrioventricular Block Following Transcatheter Aortic Valve Replacement. J Am Coll Cardiol. 2019; 73: 2538-2547.

PubMed: https://www.ncbi.nlm.nih.gov/pubmed/31118148 